\title{
BMJ Open Transformation of mortality in a remote Australian Aboriginal community: a retrospective observational study
}

\author{
Wendy E Hoy, ${ }^{1}$ Susan Anne Mott, ${ }^{1}$ Beverly June McLeod ${ }^{1,2}$
}

To cite: Hoy WE, Mott SA, McLeod BJ. Transformation of mortality in a remote Australian Aboriginal community: a retrospective observational study. BMJ Open 2017;7:e016094. doi:10.1136/ bmjopen-2017-016094

- Prepublication history and additional material for this paper are available online. To view these files please visit the journal online (http://dx.doi. org/10.1136/bmjopen-2017016094).

Received 24 January 2017 Revised 28 June 2017 Accepted 29 June 2017

CrossMark

${ }^{1}$ Faculty of Medicine, Centre for Chronic Disease, UQCCR, The University of Queensland, Brisbane, Australia

${ }^{2}$ Menzies School of Health Research, Darwin, Australia

Correspondence to

Prof. Wendy E Hoy;

w.hoy@uq.edu.au

\section{ABSTRACT}

Objectives To describe trends in ages and causes of death in a remote-living Australian Aboriginal group over a recent 50-year period.

Design A retrospective observational study, from 1960 to 2010 , of deaths and people starting dialysis, using data from local clinic, parish, dialysis and birthweight registers. Setting A remote island community in the Top End of Australia's Northern Territory, where a Catholic mission was established in 1911. The estimated Aboriginal population was about 800 in 1960 and 2260 in 2011. Participants All Aboriginal residents of this community whose deaths had been recorded.

Outcome measures Annual frequencies and rates of terminal events (deaths and dialysis starts) by age group and cause of death.

Results Against a background of high rates of low birth weight, 223 deaths in infants and children and 934 deaths in adults (age $\geq 15$ years) were recorded; $88 \%$ were of natural causes. Most deaths in the 1960s were in infants and children. However, over time these fell dramatically, across the birthweight spectrum, while adult deaths progressively increased. The leading causes of adult natural deaths were chronic lung disease, cardiovascular disease and, more recently, renal failure, and rates were increased twofold in those of low birth weight. However, rates of natural adult deaths have been falling briskly since 1986 , most markedly among people of age $\geq 45$ years. The population is increasing and its age structure is maturing. Conclusions The changes in death profiles, the expression of the Barker hypothesis and the ongoing increases in adult life expectancy reflect epidemiological and health transitions of astonishing rapidity. These probably flow from advances in public health policy and healthcare delivery, as well as improved inter-sectoral services, which are all to be celebrated. Other remote communities in Australia are experiencing the same phenomena, and similar events are well advanced in many developing countries.

\section{BACKGROUND}

Recent literature describes a rapid shift in patterns and causes of death in most countries and regions. Infant and childhood deaths have decreased, life expectancy has increased $^{1}$ and more deaths in adults are associated with non-communicable chronic diseases. ${ }^{2}$ Here we describe such a transition

\section{Strengths and limitations of this study}

The broad sweep and historical depth of this study, the unique data sources and the integration of clinical and demographic information have allowed delineation of the profound and recent transformation of mortality not previously appreciated in the Australian Aboriginal setting.

- It is inevitable that we have failed to capture some deaths in the past, which probably results in understatement of the magnitude of this transition. In some recorded natural deaths, the assignments were approximate and the contribution of multiple causes was underestimated.

in a remote-living Aboriginal Australian group over the last 51 years.

The Tiwi people live in three major communities (and several smaller ones) on Bathurst and Melville Islands off the coast of the Northern Territory (NT), about $90 \mathrm{~km}$ by sea from Darwin (figure 1). They lived in relative isolation for perhaps 7000-15000 years, and consider themselves distinct from mainland Aboriginal people, with their own unique origins, language and customs. ${ }^{3}$

In 1911, a Catholic mission was established by the Missionaries of the Sacred Heart, led by Father Francis Xavier Gsell. ${ }^{4}$ Changes followed in lifestyle (from nomadic huntergathering to living in fixed dwellings), in diet (from food from the bush and sea to depot supplies of less perishable, high caloric density food, of flour, fat, meat and sugar), in family and community structures (from polygamy and networks of carers within extended families to monogamy) and in the establishment of dormitories, schools and clinics. Transition has been especially accelerated since World War II. Cigarettes were widely introduced around this time (anecdotal evidence). The 1967 referendum formally recognised Aboriginal people in Australia ${ }^{5}$ and they were thenceforth included as residents in the national census. Legal access to alcohol began 


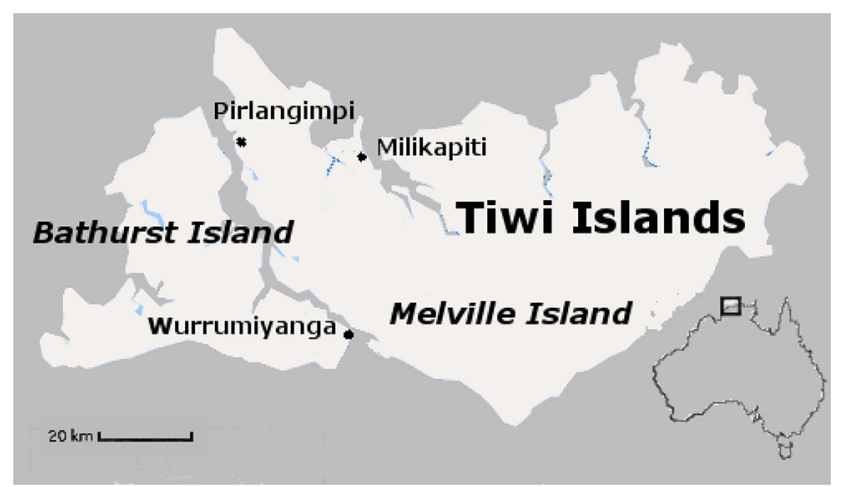

Figure 1 The Tiwi Islands, Northern Territory, Australia Note: Wurrumiyanga was formerly named Nguiu. Source: Adapted from Google Map data. The Tiwi Islands. Google; (C2017 [cited 2017 Jan 10]. Available from: https://www.google.com. au/maps/@-12.2087082,130.7314414,8.75z.

around that time. The first social club, serving alcohol, was opened in the largest Tiwi community in 1967.

Some early insights into remote-living Aboriginal people in the NT are provided by Ellen Kettle, the first Rural Survey Sister in the NT, who pioneered mobile health work in isolated areas and established individual health records, and by Dr John Hargrave, the first Aboriginal Health Officer, who examined members of many communities in 1957/1958. Both advanced understanding of Aboriginal health and development of services and policy. They described endemic conditions (yaws, malaria, infestations, trachoma) and imported conditions like leprosy, syphilis (arguably), tuberculosis, measles, small pox and influenza. They documented florid malnutrition and frank starvation, high infant and maternal mortality and conspicuously low birth weight. They then described, over time, dramatic reductions in infant mortality, the appearance of alcohol-related disorders and occasional overweight and obesity, as well as the emergence of non-communicable chronic diseases. ${ }^{67}$

These phenomena occurred against a background of continuous improvements in remote Aboriginal health services, including management of infections and infestations, immunisations, better obstetric services, better maternal and child care and cancer surveillance. Chronic non-communicable diseases, predominantly type 2 diabetes, cardiovascular disease, chronic lung disease and chronic kidney disease, now dominate the adult health profile and are the focus of most of health service provision for remote-living Australian Aboriginal adults. ${ }^{8}$

Clinical services were established by the mission, starting as first aid facilities on the beach at Nguiu (now Wurrumiyanga) on Bathurst Island. These eventually evolved into a clinic and local hospital, run by the sisters of the order of Our Lady of Sacred Heart, with additional clinics in the Melville Island communities of Milikapiti and Pirlangimpi. Medical records were established for individuals, along with clinic-based registers for births and deaths. Doctors from Darwin eventually provided backup support. More recently, there have been resident doctors for intermittent periods. Local hospital beds were closed in the early 1990s, and all persons needing hospital admission were thenceforth streamed to the Royal Darwin Hospital, transported by small plane. Responsibility for clinical services was transferred from the mission to the NT government in the early/mid-1990s.

Anthropologist Charles Hart enumerated a Tiwi population of 1062 in 1928. ${ }^{3}$ John Hargrave estimated the Tiwi population at about 800-900 in 1957, compatible with a 1954 Commonwealth Government estimate of 920. ${ }^{9} 10$ Regular government census estimates have been published every 5 years since 1986 .

Traditionally, Tiwi people have only occasionally transmigrated, usually for purposes of intermarriage according to tribal edicts. The destinations of people who travel, and the movements and locations of community members, are known by all. Deaths of people who die out of community (usually in Darwin or while visiting other communities) are documented in their medical records in their 'home' community clinic and added to the death register.

Death rates in the Tiwi community, along with those in Aboriginal people in Arnhem Land, have been the highest in Australia: in the 1990s, with age standardisation, they were six times those of the Australian mainstream. ${ }^{11}$ This generally reflects the much younger age of Tiwi people at death. Cases of kidney failure began to attract attention in the $1980 \mathrm{~s}^{12}$; for several decades, Tiwi people had the highest rates of renal failure yet described, and the first haemodialysis unit in a remote Aboriginal location was established in Wurrumiyanga on Bathurst Island in the late 1990s. High renal failure rates have followed in other remote communities. The characteristics and speculative causes of the renal disease have been described extensively. ${ }^{12-14}$ We have previously described the high rates of low birth weight in this community and the risk exacerbations for natural deaths in infants, children and young adults associated with low birth weight. ${ }^{1516}$

\section{AIMS AND OBJECTIVES}

To describe trends in mortality over more than 50 years in a remote Aboriginal community in the NT of Australia.

\section{METHODS}

Data sources were the written logs of deaths maintained by the clinics, dialysis unit records of NT Renal Services, and in this staunchly Catholic community, records maintained by the parish priests of all funerals and burials. We report recorded deaths over the 51-year period from 1960 to 2010 , beginning when recording of details of death (age, date and explanation) was becoming more systematic.

A total of 1199 deaths were recorded, and with exclusion of 34 who lacked a recorded cause of death, date of birth or date of death, 1156 were included in these analyses. Among them, some details were sometimes still lacking. 
Eighty-five of 1017 people, (8.4\%) who died as adults (at $\geq 15$ years of age) of natural causes, did not have a precise cause of death recorded: they were described as natural deaths of unknown cause. Deaths of misadventure had been clearly documented. Deaths in those age $<15$ years had clear assignments of natural or unnatural cause.

Age was documented or age group was inferred for the 1156 deaths. Analyses were conducted using broad age groups, rather than a single year of age. Sixteen death records lacked a date of birth but did have date of death and cause of death-based on cause of death, clinical judgement and local knowledge, they were assigned an age of 50 years, which put them into the category of the oldest adults ( $\geq 45$ years). Five did not have date of birth but did have date of death and their cause of death had been recorded as old age. They were assigned an age of death of 60 years, which also put them into the category of the oldest adults ( $\geq 45$ years).

Starting in the 1980s, maintenance dialysis has been available to Tiwi persons with end-stage renal disease. Numbers of patients starting treatment increased steadily until apparently stabilising at about six persons a year in the early 2000s. In this study, initiation of dialysis is considered a natural (renal) death, occurring when dialysis began, because without that treatment all participants would have died shortly thereafter. There was no additional assignment of date or cause of death when they finally expired.

Description of cause of death became more detailed over time. In the early years, the only discrimination for some deaths was of natural versus unnatural causes, while, in later years, there was more detailed narrative on cause(s) and associations of death. In the early years, deaths in people over 60 years of age often received a causal assignment of 'old age' or 'debility', but with time, 'disease-or organ-specific' assignments increased for them as well. In some recorded natural deaths, the assignments were approximate and the contribution of multiple causes was underestimated. Cause of death always took into account the previous health profile of each deceased person. In the context of sometimes sparse clinical detail, and conforming to the methodology for the Global Burden of Disease study, we derived and assigned a principal cause of death only.

Unnatural deaths, or deaths of misadventure, included those due to vehicular accidents, drownings, fire (burns and smoke inhalation), homicide, suicide, poisonings, jelly fish stings, crocodile, shark attacks and so on. We defined the main categories of natural deaths as cardiovascular (heart attack, congestive heart failure, ischaemic heart disease, coronary artery disease and stroke), respiratory (chronic lung disease, chronic obstructive airways disease, chronic bronchitis, bronchiectasis and pneumonia), renal (death with terminal renal failure and, also, after 1985, institution of dialysis in people with terminal renal failure), various other causes (eg, sepsis, liver failure, lupus, cancer, etc) and debility or old age. When there was uncertainty about deaths or persons, data were checked with several senior community members, who had lived through much of the study interval and had known most community members.

Analyses were conducted using Stata 14 (StataCorp. 2015. Stata Statistical Software: Release 14. College Station, TX: StataCorp LP). Numbers and rates of deaths were calculated by age group and cause of death. Five-year moving averages were created using the tssmooth package. Mortality rates, per 100000 population, could be calculated since 1986, the first year of the subsequent quinquennial national census that specifically enumerated Aboriginal Tiwi people. Total population estimates were also taken from census figures. ${ }^{17}$

\section{RESULTS}

Among the 1156 deaths, $222(19.2 \%)$ were in infants and children $(<1$ year and 1 to $<15$ years, respectively), and $934(78.5 \%)$ were deaths of adults (at ages $\geq 15$ years). Twenty-five $(11.3 \%)$ deaths of infants and children were deaths of misadventure and $197(88.7 \%)$ were of natural causes. Among adults, $114(12.2 \%)$ of deaths were due to misadventure and $820(87.8 \%)$ were natural deaths.

Figure 2 shows numbers of all deaths by major cause group (natural and misadventure), age group and interval (frequencies are tabulated in online supplementary table $1)$. Early on, most deaths were in infants and children. These fell rapidly at first, then more slowly. The main categories of death in infants and children were diarrhoea, respiratory disease and failure to thrive, with some cases of sudden infant death and a few congenital abnormalities. ${ }^{15}$ In 1973, a house fire killed six siblings, making a major contribution to deaths of misadventure. As infant and childhood deaths fell, numbers of deaths of adults increased. Many were among young adults (ages 15 to $<45$ years) with high numbers of both natural death and deaths of misadventure. The latter include motor vehicle accidents, drownings, homicide and suicide; there were 50 suicides $(50 \%$ of deaths of misadventure) between 1985 and 2010, of which 47 (94\%) were among males.

Since 1975, most deaths were in people of $\geq 45$ years, and most of these were of natural causes. The numbers have not perceptibly increased since the early 1990s. Only $13(2.5 \%)$ of these older adult deaths were due to misadventure.

Figure 3 shows the trends in natural deaths in adults over time, by primary causal assignment. Numbers peaked in the latter 1980s but have since had an indeterminate or falling trend. Through the mid-1980s, there were substantial numbers of natural deaths with no further details given and deaths with assignments of 'old age' or debility', but there have been more 'organsystem' assignments since the early 1990s. Among specific assignments, cardiovascular deaths and cancer/liver/ other deaths were represented over the continuum, while pulmonary (respiratory) deaths became prominent, but more recently they have been decreasing. Renal deaths become prominent in the $1980 \mathrm{~s}$; there were 25 renal 


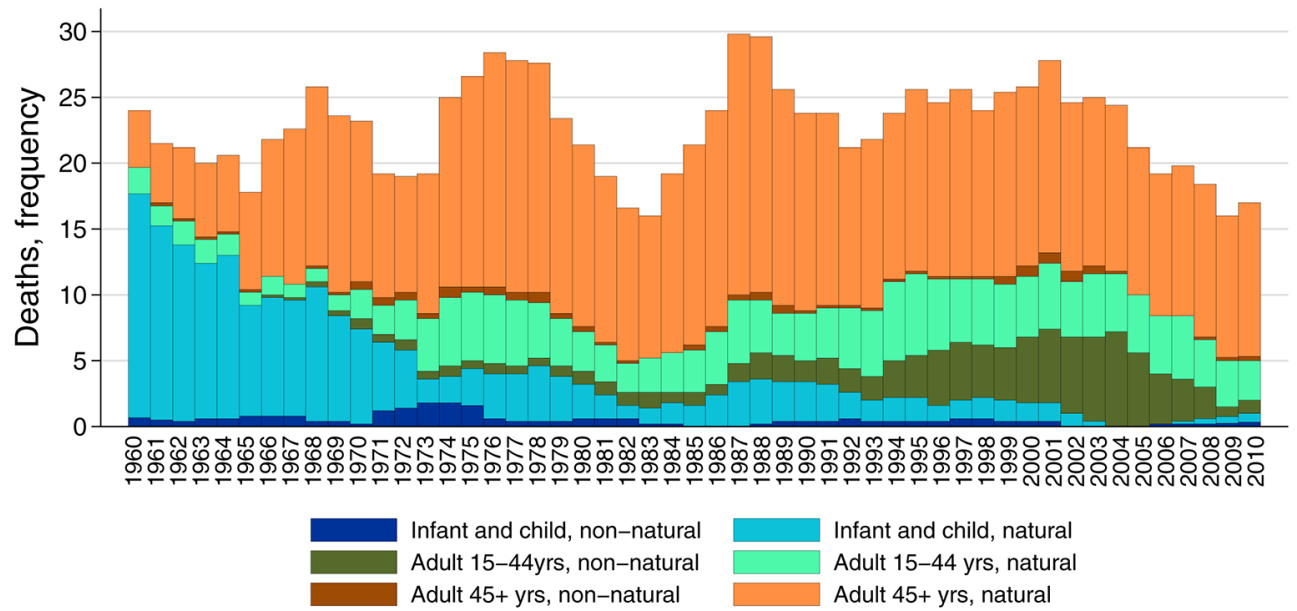

Figure 2 Numbers of Tiwi deaths by age group and broad cause of death, 1960-2010. Note: A 5-year rolling average of frequencies is presented; people who have started dialysis are included among natural deaths.

deaths in the 1980s, 42 in the 1990s and 52 from 2000 to 2009 , constituting $14.7 \%, 24.1 \%$ and $31.7 \%$ of all natural deaths in those intervals.

Figure 4 shows the smoothed estimated rates of natural deaths by age group since $1986 .{ }^{17}$ Rates of death in infants and children have fallen remarkably $(4 \mathrm{~A})$. There was an early increase in death rates among young adults (4A), followed by a progressive decline since the mid-1990s. Death rates of people age $\geq 45$ years have markedly declined, at least until the last few years of the observation interval $(4 \mathrm{~B})$. The net effect of all these changes is a decrease in overall death rates of the entire population $(4 \mathrm{C})$.

These trends are further summarised in table 1, which shows the rates of natural deaths by age group in the first and last 5-year blocks of the observation interval. Death rates of infants and children fell by $88.9 \%$, and those of young adults fell by $23.5 \%$, while those of people age $\geq 45$ years fell by $65.1 \%$. For the population as a whole, rates of natural death fell by $51.6 \%$.

Figure 5 shows that the population age structure has changed over fewer than 40 years to include higher numbers and proportions of young and middle-aged adults. ${ }^{17} 18$ In addition, the size of the total population has increased by $85 \%$.

\section{DISCUSSION}

This is the most complete description of deaths in any indigenous Australian community. It shows a profound change in patterns, rates and causes of death over a 51-year interval. Infant and childhood deaths have fallen dramatically; now most people die as adults ( $\geq 15$ years) and of natural causes. Furthermore, in the last 25 years, rates of natural deaths of adults have been falling. The population is increasing and is progressively ageing.

With improvements in prevention and treatment of infectious diseases, adult deaths are increasingly due to non-communicable diseases, with chronic lung disease, cardiovascular disease and renal disease making the greatest contribution. These chronic diseases have usually overlapped and been co-contributors to death, although this is obscured by our use of mutually exclusive categories of primary cause of adult death. Among specific

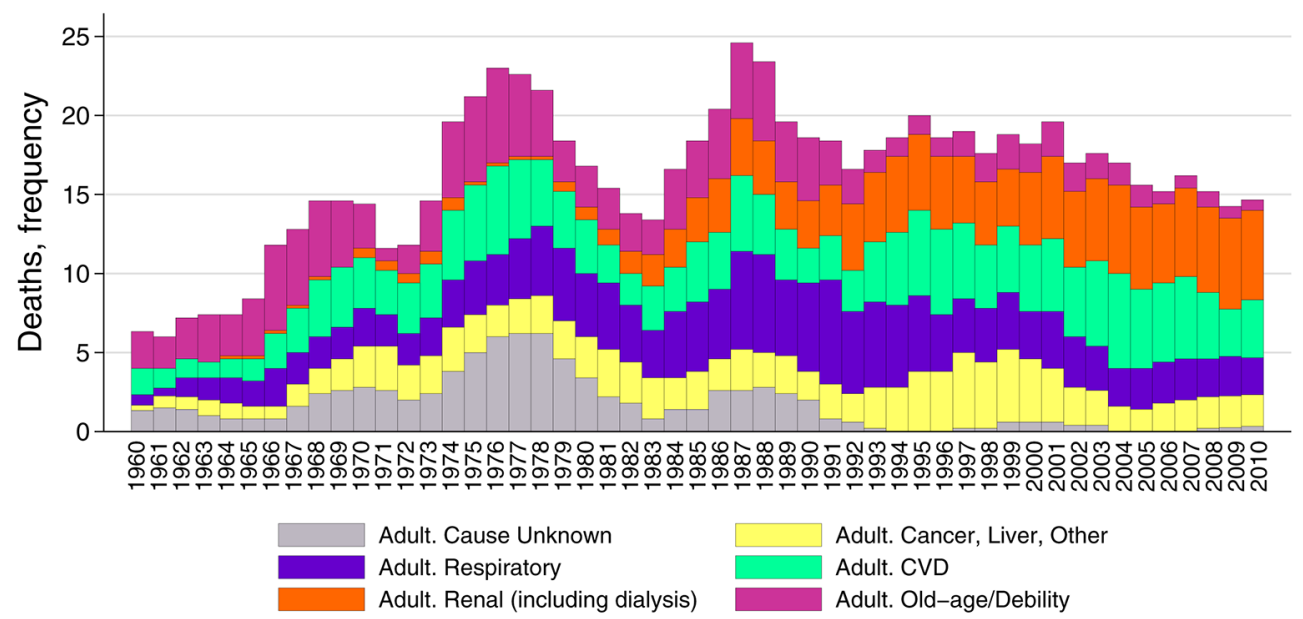

Figure 3 Numbers of Tiwi natural adult deaths by age group and cause of death, 1960-2010. Note: A 5-year rolling average of frequencies is presented; people who have started dialysis are included among renal deaths. 

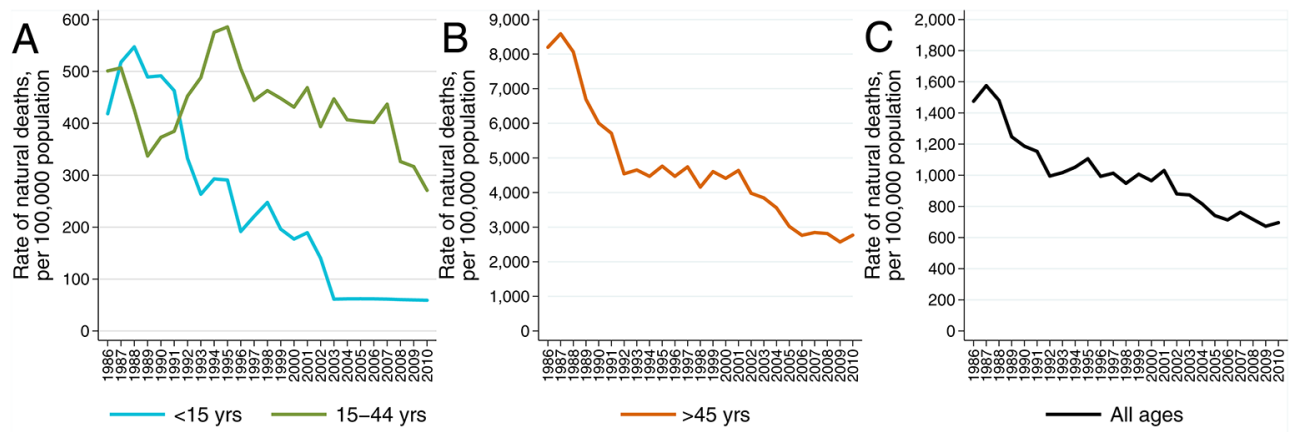

Figure 4 (A-C) Tiwi rates of natural death per 100000 population by age group, 1986-2010. Note: The figure presents a 5 -year rolling average of natural death rates by age group: $<15$ and $15-45$ years $(A) ; \geq 45$ years (B); all ages (C). People who started dialysis are included among natural deaths. The low rates of death depicted for those $<15$ years from 2003 to 2010 are each based upon the average of the very small number of events (four) that occurred between 2001 and 2010 . Sources of 1986-2010 population data: quinquennial census estimates (Australian Bureau of Statistics Catalogues: 1987, \#2460.0; 1993, \#2730.7; 2000, \#70609; 2007, \#2001.0; 2002, \#2002.0; 2012, \#2002.0). ${ }^{17}$

assignments, cardiovascular deaths and cancer/liver/ other deaths have been represented over several decades, while pulmonary deaths became prominent in the 1970s but have decreased since the early 1990s. Kidney failure has become prominent since the 1980s and is now the leading single assignment.

The still excessive (although improving) rates of natural deaths are compatible with the 'Barker hypothesis', which proposes that survivors of lower birth weights have accentuated susceptibility to chronic diseases and premature natural death in adult life. ${ }^{151619}$ We have shown that the dramatic reductions in early-life mortality have been experienced across the birthweight spectrum so that, against a background of seriously low birth weights, large cohorts of underweight infants, who were previously at greatest risk for early death, have now survived to adult life. As adults, they have enhanced susceptibility to chronic disease, as we have demonstrated. ${ }^{152021}$ Through 2010, rates of natural adult deaths before the age of 41 years, in Tiwi people of low birth weight, were twice that of those with higher birth weights, with the greatest accentuation of risk being for pulmonary deaths, a sixfold increase. ${ }^{16}$

The continued evolution of the chronic disease rates and patterns and rates over time is probably influenced by improving birth weights, changing age structure among adults, improved prevention, screening and management of chronic disease and changes in competing causes of deaths. With reductions in deaths from pulmonary disease and postponement of cardiovascular deaths, flowing from a secular increase in birth weights, ${ }^{13}$ and from better medical management, coexisting nephropathy has more opportunity to pursue its more leisurely course to renal failure. ${ }^{22}$ We have published extensively on the expression, course and biopsy representation of the underlying renal disease.$^{12}$ It is clearly multideterminant, with risk enhanced by low birth weights, inflammation and infection, episodes of poststreptococcal glomerulonephritis and higher body mass indices and diabetes in adult life. ${ }^{2324}$

Availability and use of the clinic-based death records and the supporting parish burial records set this study apart. The NT-wide government register of deaths dates only back to the mid-1980s, and in that register, community assignment has sometimes been incomplete. Moreover, government records do not capture the full burden of renal failure, due to deficient documentation of a renal cause of death, in people receiving renal replacement therapy (RRT) and in those dying of renal failure without receiving RRT. ${ }^{1425}$ Our composite definition of 'renal deaths' as the start of RRT and a renal death without RRT more fully reveals the burden of renal failure disease. That approach is necessary for monitoring, prevention and intervention strategies, especially in the context of the burden and costs of RRT. ${ }^{13}{ }^{26}$ Furthermore, it is the only way that kidney failure rates can be compared with populations in other countries for whom RRT is not widely available.

Our data also reveal an excess of deaths by misadventure in young adults in more recent years. Such deaths, often alcohol or drug-fuelled, are prominent among young Aboriginal adults nationwide, and are of grave concern. ${ }^{27} 28$

Limitations include the fact that some Tiwi deaths were probably not captured in our data sources. This is

Table 1 Mean $(95 \% \mathrm{Cl})$ natural death rate per 100000 population by 5 -year intervals and age group

\begin{tabular}{lllll}
\hline Time interval & $<15$ years & 15-44 years & 45+ years & All ages \\
\hline $1986-1990$ & $547.4(406$ to 689$)$ & $426.3(240$ to 613$)$ & $8065.4(6778$ to 9353$)$ & $1480.7(1240$ to 1721$)$ \\
\hline $2006-2010$ & $60.5(0$ to 202$)$ & $326.3(140$ to 513$)$ & $2815.2(1528$ to 4103$)$ & $716.8(476$ to 957$)$ \\
\hline
\end{tabular}

Note: The mean of aggregate natural deaths over years 2001-2010 is used for deaths of those $<15$ years of age.

Sources, 1986-2011 census data, Australian Bureau of Statistics (Catalogues: 1987, \#2460.0; 2012, \#2002.0). ${ }^{17}$ 

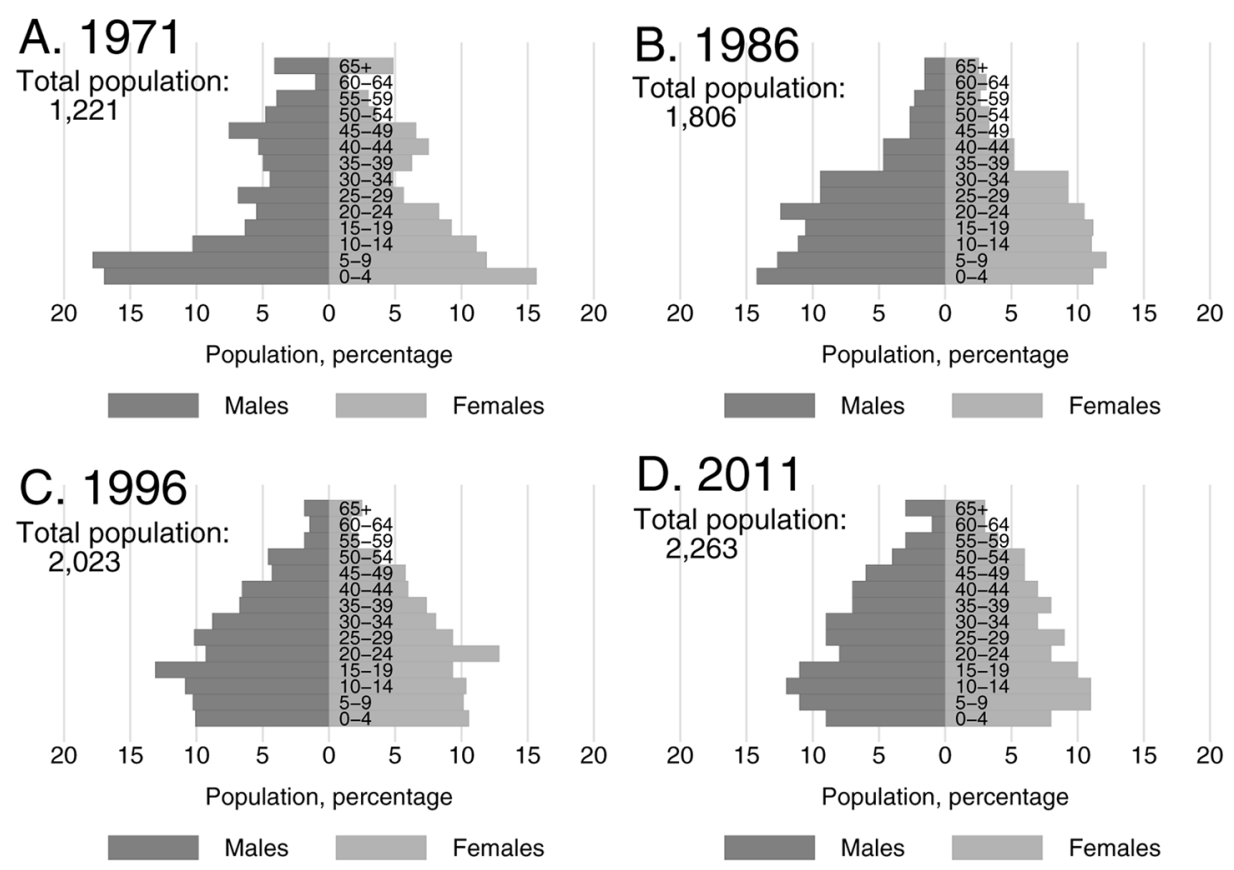

Figure 5 (A-D) Age distribution of the Tiwi population at four time-points, by sex, 1971-2011. Note: The figure presents population pyramids and total population for 1971 (A), 1986 (B), 1996 (C) and 2011 (D). Sources: (A) cited in Peterson, 1988 ${ }^{18}$; (B-D) census data, Australian Bureau of Statistics (Catalogues: 1987, \#2460.0; 2000, \#70609; 2012,\#2002.0). ${ }^{17}$

more likely in the earlier years, so that that the earlier numbers and rates of deaths, as well as the subsequent fall in deaths, have probably been understated. Moreover, from 1985 to 2009, the government agencies recorded $18 \%$ fewer deaths for the Tiwi community than we have recorded, with underidentification varying from $10 \%$ to $30 \%$ over five consecutive 5-year intervals (In an email from Y Zhao (yuejen.zhao@nt.gov.au), 24 October 2016). An additional limitation is assignment of a single category of cause of death, whereas natural deaths in adults have multiple causes and associated conditions; the coexistence of cardiovascular risk and lung disease and of renal disease with cardiovascular disease are well recognised.

Is it credible that about half the deaths in Tiwi people in the 1960s were in subjects less than 15 years of age? The WHO estimated that, in 1955, fully $40 \%$ of global deaths were in children age $<5$ years, so presumably, an even greater proportion were deaths of people $<15$ years old. ${ }^{29}$ Furthermore, skeletal remains of some premodern cultures have suggested that up to $68 \%$ of deaths occurred in people $<15$ years old (Chamberlain cited in Roser, 2006) ${ }^{1}{ }^{30}$ Hart's comment that, around 1928, five of 15 bestowed wives (females promised in marriage to specific Tiwi community members) died before puberty, supports a high childhood mortality. ${ }^{3}$

Other Aboriginal groups in remote areas of Australia over the same intervals have undoubtedly experienced similar transitions. NT government agencies have described similar trends in early-life mortality since 1967 and improvements in natural death rates overall since the late 1980 s (figures 6 and 7 ). ${ }^{31}$ In the Shire of Broome, Western Australia, Gracey et al described excessive levels of Aboriginal infant and childhood infection and undernutrition in the 1970s and 1980s and increasing deaths by misadventure in young Aboriginal adults between 1971 and $1994 .^{32}$ Our findings are also consistent with events in many other countries and regions. Figure 8 shows the fall in early-life mortality since 1960 , which is most dramatic in disadvantaged populations like Yemen, Afghanistan, Bangladesh and Nepal, ${ }^{33}$ while figure 9 shows

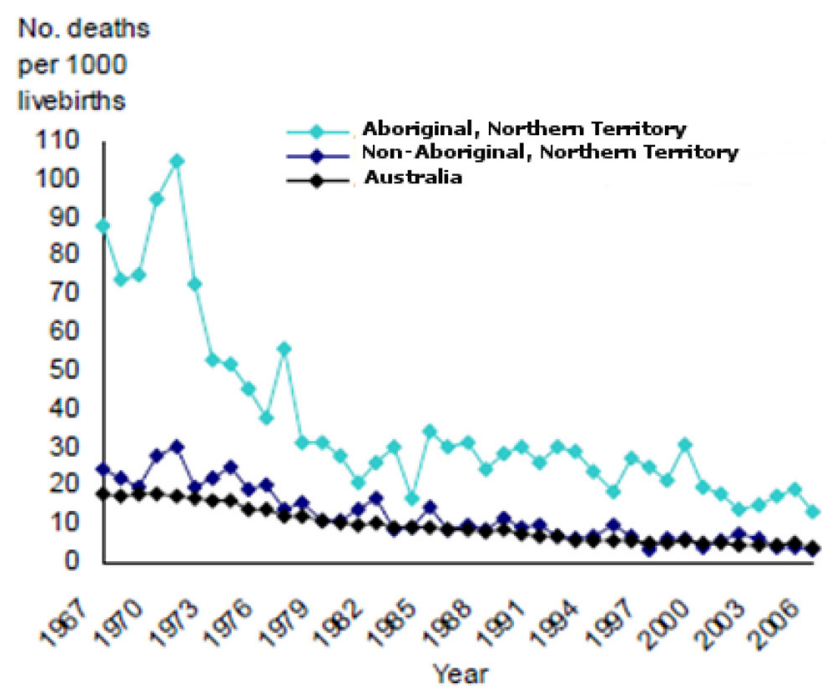

Figure 6 Infant mortality, Northern Territory and Australia, 1967-2007. Source: Northern Territory Department of Health, 2011.31 


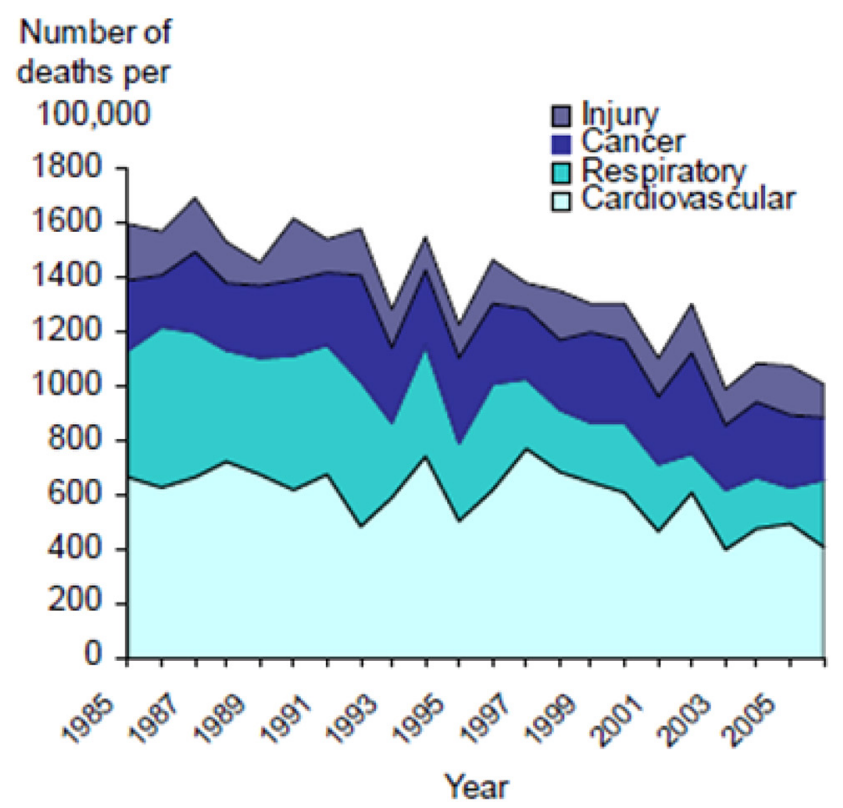

Figure 7 Leading causes of death in the Aboriginal population of the Northern Territory, 1985-2006. Source: Northern Territory Department of Health, 2011. ${ }^{31}$

the simultaneous increase in life expectancy at birth, again most marked in disadvantaged settings. ${ }^{34}$ Our Tiwi data show that the improvement in life expectancy is a function of reduced early-life morality as well as increasing adult longevity.

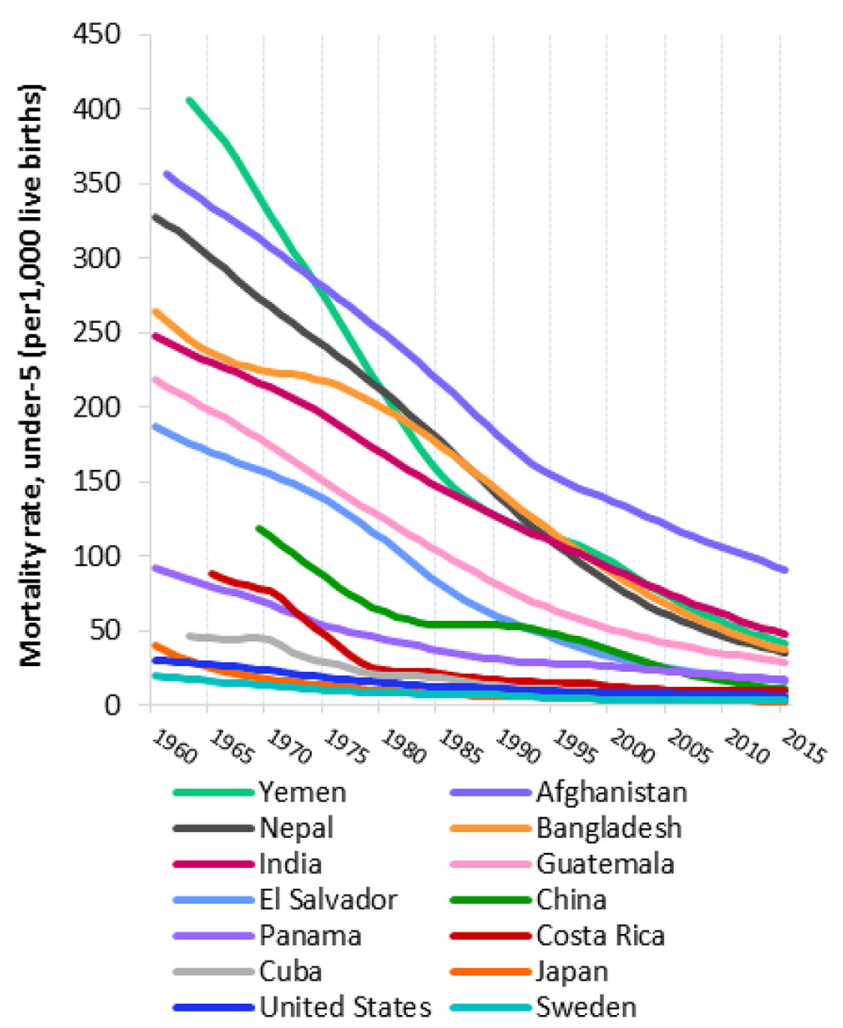

Figure 8 Under-five mortality rates for selected countries, 1960-2015. Source: adapted from UNICEF Global Database, $2015^{33}$

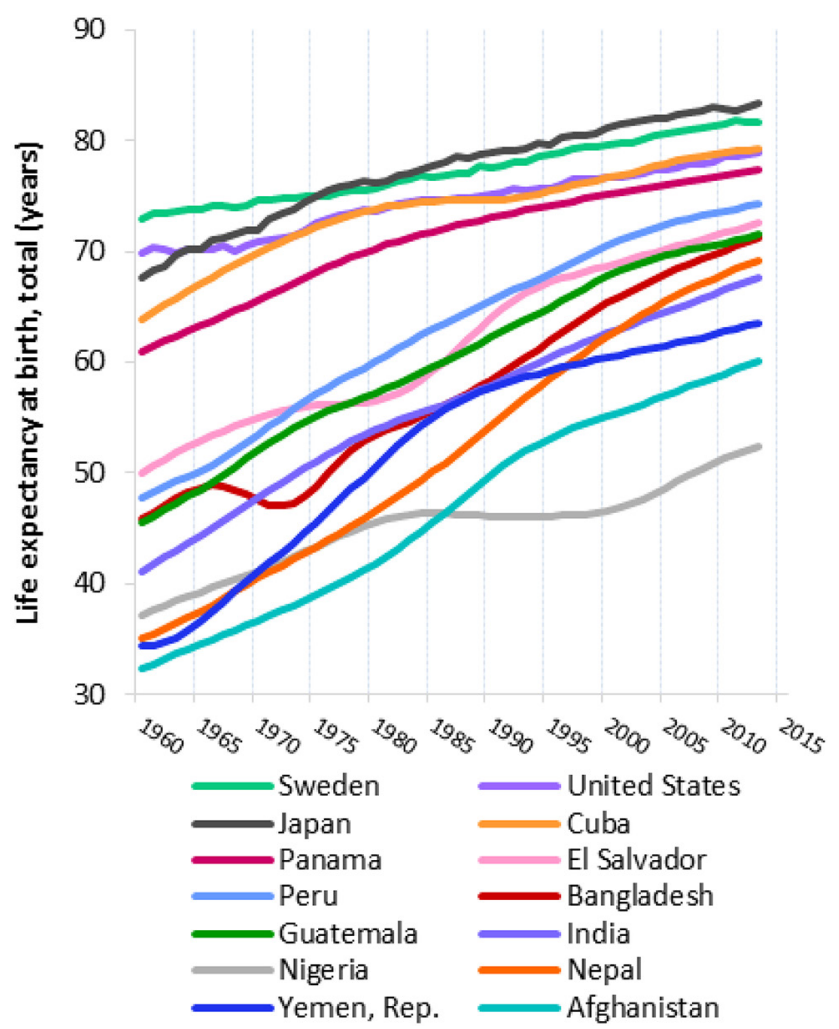

Figure 9 Life expectancy at birth for selected countries, 1960-2013. Source: adapted from The World Bank, 2016. ${ }^{34}$ Source notes: Derived from male and female life expectancy at birth from sources such as United Nations Population Division, World Population Prospects and United Nations Statistical Division; Population and Vital Statistics Report (various years); census reports and other statistical publications from national statistical offices; Eurostat, Demographic Statistics; Secretariat of the Pacific Community: Statistics and Demography Programme; and US Census Bureau: International Database.

Gratifying as these reductions in adult death rates are, further improvements can still be anticipated. Birth weights continue to increase so that accentuated chronic disease risk from that source should decline. In addition, adult health services continue to improve, especially in prevention, screening and management of chronic disease, ${ }^{8}$ and rates of smoking are falling. ${ }^{35}$ Current challenges in all of remote Aboriginal Australia, however, include high rates of obesity ${ }^{36}$ and poor diet, especially sugar excess, ${ }^{37}$ drug use, alcohol abuse and foetal alcohol syndrome $^{7}$. Rates of interpersonal violence, as well as of suicide and accidents, remain high.

These changes described in the manuscript are especially welcome news for the Tiwi Aboriginal people, whose mortality rates have been the worst in Australia, ${ }^{11}$ and for remote-living Aboriginal people more broadly. They represent triumphs of inter-sectoral improvements, public health policy and healthcare more broadly, which are to be celebrated. Healthcare providers and policy-makers should be comforted to see such large-scale progress demonstrated through an historical perspective and 
encouraged in their resolve for ongoing improvements in preventative healthcare. ${ }^{8}$ Better education, skills training, employment opportunities, empowerment and socioeconomic status must also be unflaggingly supported. More broadly, this information should moderate the negative discourse which has pervaded the Aboriginal health literature.

Acknowledgements We are very grateful to Tiwi Land Council and the Tiwi people for their continuing support of this research. We specifically acknowledge the expertise and dedication of the sisters of the order of Our Lady of the Sacred Heart who maintained fastidious clinical records which now underlie much of this report. We are grateful to the clinic staff in the communities of Wurrumiyanga (previously known as Nguiu) on Bathurst Island and of Milikapiti and Pirlangimpi on Melville Island. We thank the Catholic Diocese of Darwin for allowing access to the medical records and supplying records of deaths and burial recorded by the parish. We thank NT Renal Services for supplying records of Tiwi people who started dialysis. We thank Centre of Chronic Disease staff for their contribution to data management and analyses throughout the course of this and related projects.

Contributors WEH conceived and designed this work, collected data, directed data analyses, interpreted the findings and wrote the manuscript. BJML conducted field work and performed data collection and data preparation. SAM prepared data, performed analyses and contributed to interpretation, produced figures and tables and coordinated preparation and editing of the manuscript. All authors had full access to all of the data in the study and can take responsibility for the integrity of the data and the accuracy of the data analysis. All authors reviewed, revised and approved the manuscript.

Funding This work has been supported by past grants from the National Health and Medical Research Council of Australia (NHMRC) (\#511081, \#921134, \#951250 and \#951342) and from the Colonial Foundation of Australia. It is currently supported by the NHMRC Centre of Research Excellence in Chronic Kidney Disease in Australia (\#1079502). Past grants have specifically supported patient recruitment, data collection and data management of a broader study within which this study is embedded. Current support has enabled analyses and preparation of this manuscript. The funders had no role in preparation or conduct of the study or writing or submission of the manuscript.

Competing interests All authors have completed the ICMJE uniform disclosure form at www.icmje.org/coi_disclosure.pdf and declare the following: authors had financial support from National Health and Medical Research Council of Australia (Centre for Research Excellence in Chronic Kidney Disease, APP1079502, and or Australia Fellowship, APP511081) for the submitted work; no financial relationships with any organisations that might have an interest in the submitted work in the previous 3 years; and no other relationships or activities that could appear to have influenced the submitted work.

Ethics approval Human Research Ethics Committee of the Northern Territory Department of Health and Community Services and Menzies School of Health Research.

Provenance and peer review Not commissioned; externally peer reviewed.

Data sharing statement Grouped, de-identified data can be requested from the Corresponding Author, Wendy E Hoy (w.hoy@uq.edu.au).

Open Access This is an Open Access article distributed in accordance with the Creative Commons Attribution Non Commercial (CC BY-NC 4.0) license, which permits others to distribute, remix, adapt, build upon this work non-commercially, and license their derivative works on different terms, provided the original work is properly cited and the use is non-commercial. See: http://creativecommons.org/ licenses/by-nc/4.0/

(c) Article author(s) (or their employer(s) unless otherwise stated in the text of the article) 2017. All rights reserved. No commercial use is permitted unless otherwise expressly granted.

\section{REFERENCES}

1. Roser M. Population: life expectancy. child mortality. http:// ourworldindata.org/ (accessed 18 Aug 2016).

2. Lozano R, Naghavi M, Foreman K, et al. Global and regional mortality from 235 causes of death for 20 age groups in 1990 and 2010: a systematic analysis for the global burden of disease study 2010 . Lancet 2012;380:2095-128.

3. Hart CWM, Pilling AR, Goodale JC. The Tiwi of North Australia. New York: Holt, Rinehart and Winston, 1988.

4. National Archives of Australia. Bishop Francis Xavier Gsell MSC-Fact sheet 151. National Archives of Australia. 2016. http://www.naa.gov. au/collection/fact-sheets/fs151.aspx

5. Commonwealth of Australia. Handbook of the 44th Parliament (2014) "Part 5 - Referendums and Plebiscites - referendum results": Parliamentary Library of Australia. http://parlinfo.aph.gov.au/parllnfo/ download/handbook/newhandbook/2014-10-31/toc_pdf_repeat/ Part\%205\%20-\%20Referendums\%20and\%20Plebiscites.pdf; fileType=application\%2Fpdf (accessed 26 Dec 2016).

6. Kettle E. Health Services in the Northern Territory - a history 1824-1970. Volume 2. Darwin: Australian National University. North Australia Research unit, 1991. https://digitalcollections.anu.edu.au/ handle/1885/46992 (accessed 18 Aug 2016).

7. Hargrave JC. The best of both worlds: aboriginal health then and now. the Seventh Eric Johnston Lecture, 1992. Occasional papers; no. 36. Darwin: State Library of the Northern Territory, 1993. https:// www.nt.gov.au/_data/assets/pdf_file/0008/241892/occpaper36.pdf (accessed 18 Aug 2016).

8. Hoy WE. Chronic disease care in remote Aboriginal Australia has been transformed. BMJ 2013;347:f6127.

9. Hargrave J. Medical survey of the Bathurst Island Mission. MarchMay 1957. Report to the NT Department of Health, 1957. Darwin: Australian Archives, 1957.

10. Commonwealth of Australia. The Northern Territory Report: 19531955. Canberra: Commonwealth Government, 1956. http://aiatsis. gov.au/sites/default/files/catalogue_resources/59270.pdf (accessed 23 Aug 2016).

11. Jain SK, ed. Trends in mortality by causes of death in Australia, the States and Territories during 1971-1992, and in statistical subdivisions during 1991-1992. cat. no. 3313.0. Canberra: National Centre for Epidemiology and Population Health and Australian Bureau of Statistics, 1994. http://www.ausstats.abs.gov.au/ausstats /free.nsf/0/8C850BD253D26CE3CA25722500049511/\$File/33130_ 1971-92.pdf (accessed 2016 Aug 18).

12. Spencer JL, Silva DT, Snelling P, et al. An epidemic of renal failure among Australian Aboriginals. Med J Aust 1998;168:537-41.

13. Australian Indigenous HealthInfoNet. Chronic conditions: review of kidney disease among indigenous people. $2015 \mathrm{http}: / / \mathrm{www}$. healthinfonet.ecu.edu.au/chronic-conditions (accessed 1 Sep 2016).

14. Hoy WE, Mott SA, Mc Donald SP. An expanded nationwide view of chronic kidney disease in Aboriginal Australians. Nephrology 2016;21:916-22.

15. Hoy WE, Nicol JL. Birthweight and natural deaths in a remote Australian Aboriginal community. Med J Aust 2010;192:14-19.

16. Hoy WE, Nicol JL. The Barker hypothesis confirmed: association of low birthweight and all-cause natural deaths in adults in a remote Australian Aboriginal community. Submitted to J Dev Orig Health Dis 2017.

17. Australian Bureau of Statistics. Historical Reference and Information: ABS, Commonwealth of Australia, 2013. http://www.abs.gov.au/w ebsitedbs/censushome.nsf/home/historicalinformation?opendocume nt\&navpos=320 (accessed 11 Sep 2016).

18. Peterson N, Taylor J. Demographic transition in a hunter-gatherer population the Tiwi case, 1929-1996. Australian Aboriginal Studies 1998;1:11-27.

19. Barker DJ, Osmond C, Golding J, et al. Growth in utero, blood pressure in childhood and adult life, and mortality from cardiovascular disease. BMJ 1989;298:564-7.

20. Hoy WE, Rees M, Kile E, et al. Low birthweight and renal disease in Australian Aborigines. Lancet 1998;352:1826-7.

21. Singh GR, Hoy WE. The association between birthweight and current blood pressure: a cross-sectional study in an Australian Aboriginal community. Med J Aust 2003;179:532-5.

22. Grams ME, Coresh J, Segev DL, et al. Vascular disease, ESRD, and Death: interpreting competing risk analyses. Clinical Journal of the American Society of Nephrology 2012;7:1606-14.

23. Hoy WE, Kincaid-Smith P, Hughson MD, et al. Invited review for World Kidney Forum, CKD in Aboriginal Australians. American Journal of Kidney Diseases 2010;56:983-93.

24. Hoy WE, Kondalsamy Chennakes S, McDonald SP, et al; Chronic kidney disease in Aboriginal Australians. El Nahas M, ed. Kidney disease in ethnic minorities and the developing world. New York, U.s: taylor \& Francis, 2005:305-33.

25. Australian Institute of Health and Welfare. Assessment of the coding of ESKD in deaths and hospitalisation data. A working paper using linked hospitalisation and deaths data from Western Australia and New South Wales. Canberra: AlHW, 2014. Cat. no. PHE 182. 
26. You J, Hoy W, Zhao Y, et al. End-stage renal disease in the Northern Territory: current and future treatment costs. Med J Aust 2002;176:461-5.

27. Australian Bureau of Statistics. Leading causes of Aboriginal and Torres Strait Islander deaths. 3303.0 cuases of death, Australia, 2013 Commonwealth of Australia, 2015. http://www.abs.gov.au/ausstats/ abs@.nsf/Lookup/by\%20Subject/3303.0 2013 Main\%20Features Leading\%20Causes\%20of\%20Aboriginal\%20and\%20Torres\% 20Strait\%20Islander\%20Deaths 10015 (accessed 01 Jan 2016).

28. Australian Indigenous HealthInfoNet. Summary of Aboriginal and Torres Strait Islander health, 2015. 2016 http://www.healthinfonet. ecu.edu.au/health-facts/summary (accessed 01 Jan 2016).

29. World Health Organization. 50 facts: global health situation and trends 1955-2025: World Health Report, 2016. Available from. http:// www.who.int/whr/1998/media_centre/50facts/en/ (accessed 23 Aug 2016)

30. Hill K. The decline of childhood mortality: John Hopkins University, 1990. https://jscholarship.library.jhu.edu/handle/1774.2/936 (accessed 23 Aug 2016).

31. Northern Territory Department of Health. Mortality in the Northern Territory 1967-2006. 2011 http://hdl.handle.net/10137/480 (accessed 26 Aug 2016).
32. Gracey M, Spargo RM. Deaths in Broome, Western Australia, 1883 to 1994. Aust N Z J Public Health 1996;20:505-11.

33. Database UG. Child Mortality estimates: country-specific under-five mortality rate: UNICEF, 2015. http://data.unicef.org/child-mortality/ under-five.html (accessed 23 Aug 2016).

34. The World Bank. Life expectancy at birth, total (years): World development indicators. World Bank Group IBRD IDA, 2016. http:// data.worldbank.org/indicator/SP.DYN.LE00.IN\%20Ditto (accessed 23 Aug 2016).

35. Australian Bureau of Statistics, National Aboriginal and Torres Strait Islander Social Survey, 2014-15. cat no. 4714.0. ABS 2016. http://www.abs.gov.au/ausstats/abs@.nsf/Lookup/4714.0main+ features122014-15 (accessed 23 Aug 2016).

36. Australian Bureau of Statistics. Australian Aboriginal and Torres Strait Islander Health survey: updated results, 2012-2013. 2014. Cat no. 4727.0.55.006 http://www.abs.gov.au/ausstats/abs@.nsf/Lookup/ by $\% 20$ Subject/4727.0.55.006 2012\%E2\%80\%9313 Main\% 20Features Overweight\%20and\%20obesity 12 (accessed 23 Aug 2016).

37. Hoy WE, Manning RW, Tungatalum L, et al. A profile of sales audits of a remote aboriginal community's general store: 1992 and 2011. ANZJPH, Letter, 2014;38:94. 